\title{
Estimating eligibility for lung cancer screening in an Australian cohort, including the effect of spirometry
}

$\mathrm{L}$ ung cancer causes more deaths than any other cancer, and is a leading cause of disease-related burden in Australia. ${ }^{1}$ The United States National Lung Screening Trial (NLST) showed that screening high risk current and former smokers for lung cancer with low dose chest computed tomography (LDCT) can significantly reduce lung cancer mortality. ${ }^{2}$ LDCT lung cancer screening is recommended in the US for eligible individuals.

Unlike other cancer screening programs that select participants according to the risk factors of age and sex, eligibility for lung cancer screening is more complex. The current US screening criteria, as defined by the US Preventive Service Task Force (USPSTF), are that current or former smokers are eligible if they are aged 55-80 years, have a smoking history of at least 30 pack-years, and, if a former smoker, have quit less than 15 years ago. ${ }^{3}$ However, this approach is not necessarily the most efficient for identifying those who may benefit from screening. ${ }^{4}$ Using probabilistic multivariate lung cancer risk prediction models to select individuals for screening may improve overall efficiency and costeffectiveness, and are recommended by international organisations..$^{5-7}$

The $\mathrm{PLCO}_{\mathrm{m} 2012}$ lung cancer risk model was developed during the US Prostate, Lung, Colorectal, Ovarian Screening (PLCO) Trial, and has been validated in the NLST cohort. ${ }^{8}$ This model uses data on age, smoking status, duration and intensity, family history, body mass index (BMI), and comorbidities (including selfreported chronic obstructive pulmonary disease [COPD], chronic bronchitis and emphysema) to estimate an individual's risk of developing lung cancer within 6 years. ${ }^{8} \mathrm{~A}$ $\mathrm{PLCO}_{\mathrm{m} 2012}$ lung cancer risk of greater than $1.5 \%$ has been proposed as an

Abstract

Objectives: To estimate the proportion of ever-smokers who are eligible for lung cancer screening in an Australian cohort, and to evaluate the effect of spirometry in defining chronic obstructive pulmonary disease (COPD) when assessing screening eligibility.

Design: Cross-sectional study of 3586 individuals aged 50-68 years who live in the Busselton Shire of Western Australia.

Outcomes: Proportion of ever-smokers eligible for lung cancer screening based on United States Preventive Services Task Force (USPSTF) criteria, and $\mathrm{PLCO}_{\mathrm{m} 2012}$ lung cancer risk $>1.5 \%$. The effect of using self-reported COPD, symptoms consistent with COPD, or spirometry to define COPD for screening eligibility according to the $\mathrm{PLCO}_{\mathrm{m} 2012}$ criteria.

Results: Of ever-smokers aged 55-68 years, 254 (20.1\%) would be eligible for screening according to USPSTF criteria; fewer would be eligible according to $\mathrm{PLCO}_{\mathrm{m} 2012}$ criteria $(225,17.9 \% ; P=0.004)$. This is equivalent to $8.9-10.0 \%$ of the total population aged $55-68$ years, which suggests about 450000 individuals in Australia may be eligible for lung cancer screening. The proportions of eligible participants were not significantly different whether spirometry results or symptoms consistent with COPD were used to determine $\mathrm{PLCO}_{\mathrm{m} 2012}$ risk.

Conclusions: The proportion of ever-smokers in this population who were eligible for lung cancer screening was 17.9-20.1\%. Using symptoms to define COPD is an appropriate surrogate measure for spirometry when determining the presence of COPD in this population. There are significant challenges for policy makers on how to identify and recruit these eligible individuals from the wider population.

alternative lung cancer screening eligibility criterion. ${ }^{9}$

COPD is an independent risk factor for the development of lung cancer, and self-reported, doctor-diagnosed COPD and chronic bronchitis or emphysema are included in the $\mathrm{PLCO}_{\mathrm{m} 2012}$ risk prediction model (but not in the USPSTF eligibility criteria). ${ }^{8}$ There are, however, significant differences in the proportions of individuals who report a diagnosis of COPD, who have symptoms consistent with COPD, or who have airflow obstruction detectable by spirometry. ${ }^{10}$ Including airflow obstruction improves the accuracy of a lung cancer risk prediction that does not incorporate self-reported COPD. ${ }^{11}$ Incorporating spirometry results into eligibility assessment for lung cancer screening has been suggested, but the impact of adding spirometry-defined COPD to the existing eligibility criteria of selfreported COPD or symptoms consistent with COPD is not known. ${ }^{12}$

In Australia, about 2.2 million people aged 55-75 years are current or former smokers, but the proportion of those eligible for lung cancer screening, using either USPSTF or PLCO $_{\mathrm{m} 2012}$ criteria, is unknown. ${ }^{13}$ Estimating the proportion of people eligible for lung cancer screening will both aid policy makers when planning future capacity and assessing infrastructure requirements, and help estimate screening participation rates.

The aims of this study were to estimate the proportion of an Australian cohort that is eligible for lung cancer screening, and to examine the utility of including spirometry-defined COPD as part of screening eligibility assessment. 


\section{Methods}

The Busselton Healthy Ageing Study (BHAS) is a cross-sectional study of adults born between 1946 and 1964 who live in the Busselton Shire of Western Australia. ${ }^{14}$ Participants were recruited sequentially at random between 2010 and 2013 from the electoral roll; the participation rate was greater than $80 \%$ of contacted individuals. Participants completed a self-administered questionnaire and physical assessments, including spirometry. The upper age limit of participants included in our study (68 years) was determined by the BHAS design.

Smoking status, duration and intensity were self-reported. Ever-smokers responded positively to "Have you ever smoked cigarettes?" Current smokers responded positively to "Do you currently smoke manufactured or hand-rolled cigarettes?", and former smokers responded negatively. Packyears of smoking were determined by multiplying the duration of smoking in years by the number of 20-cigarette packs smoked each day. Personal history of any cancer other than nonmelanomatotic skin cancer, family history of lung cancer, and other demographic information were selfreported.

BMI was calculated from the measured height and weight. Preand post-bronchodilator forced expiratory volume in one second $\left(\mathrm{FEV}_{1}\right)$ and forced vital capacity (FVC) were measured using an EasyOne spirometer (NDD Medical Technologies) before and after administration of $200 \mu \mathrm{g}$ of inhaled salbutamol with a metered dose inhaler and spacer. Participants were asked to withhold any bronchodilator medication, if possible, for 12 hours before testing.

Individuals were excluded from the analysis if they had a history of lung cancer, if BMI or demographic data were missing, or there was insufficient data on smoking duration or intensity to calculate the number of pack-years.

Lung cancer risk was calculated with the $\mathrm{PLCO}_{\mathrm{m} 2012}$ 6-year lung cancer risk prediction model. ${ }^{8}$ For the purposes of this model, COPD was defined in three ways:

- self-reported, doctor-diagnosed COPD, defined as a positive response to "Has your doctor ever told you that you had COPD?";

- symptoms consistent with COPD, defined as a positive response to "Do you cough on most days for as much as 3 months each year?" or "Do you bring up phlegm from your chest on most days for as much as 3 months each year?" or "Has your chest made a wheezing or whistling sound in the last 12 months?"; and

- spirometry-defined

COPD, defined by the presence of postbronchodilator airflow obstruction $\left(\mathrm{FEV}_{1} / \mathrm{FVC}\right.$ ratio <0.7), excluding those with more than $12 \%$ improvement in $\mathrm{FEV}_{1}$ or FVC after bronchodilator medication.

Eligibility for lung cancer screening was based on two criteria: the current USPSTF recommendation ${ }^{3}$ and a $\mathrm{PLCO}_{\mathrm{m} 2012}$ 6-year lung cancer risk of $>1.5 \%$, as recommended by Tammemägi and colleagues. ${ }^{8}$ To estimate the proportion of the Australian population who are eligible for screening, an estimate of 2.2 million Australians aged $55-75$ years who are current or former smokers ${ }^{13}$ was multiplied by our estimate of the proportion of potentially eligible ever-smokers in the Busselton population according to USPSTF criteria.

Statistical analyses were performed in SPSS 22 (IBM); 95\% confidence intervals for proportions were calculated using continuity adjustment. Comparisons of the proportions of independent and dependent samples were performed with $\chi^{2}$ and McNemar tests respectively. Independent sample $t$ tests compared the means of independent samples. Statistical significance was defined as $P<0.05$.

\section{Ethics approval}

The BHAS and the reported study received human research ethics approval from the University of Western Australia Human Research Ethics Committee (references RA/4/ A/2203, RA/4/1/7891).

\section{Results}

Of all 3586 BHAS participants aged 50-68 years, 1903 (53.1\%) were current or former smokers. Of these ever-smokers, 36 were excluded (16 had incomplete smoking information, 15 reported smoking less than one cigarette per day, one had prior lung cancer, and demographic or BMI data were missing for four), leaving 1867 participants for the analysis. In the 55-68-year-old age group, $1260(49.9 \%)$ were ever-smokers (including $240 \quad[6.7 \%]$ current smokers), 1241 (49.2\%) were neversmokers, and 22 (0.9\%) had incomplete smoking data.

The demographic details of all BHAS ever-smokers in two age groups, 50-68 years and 55-68 years, are summarised in Box 1. The 55-68year-old age group was selected as corresponding to the age cohort currently eligible for lung cancer screening in the US.

\section{Eligibility for lung cancer screening}

Of ever-smokers aged 55-68 years, 254 (20.1\%; 95\% CI, 17.9-22.3\%) would be eligible for screening according to USPSTF criteria. Using the $\mathrm{PLCO}_{\mathrm{m} 2012}$ criteria with self-reported COPD, fewer people (225, 17.9\%) would be eligible $(95 \%$ CI, $15.8-20.0 \%$; $P=0.004)$.

The proportion of ever-smokers eligible for screening increased with age in the PLCO $_{\mathrm{m} 2012}$ model, but was stable when using USPSTF criteria (Box 2). Of the entire agedefined cohort, $2.6 \%$ would be eligible using $\mathrm{PLCO}_{\mathrm{m} 2012}$ criteria but not according to USPSTF criteria, and $4.9 \%$ would be eligible using USPSTF criteria but not $\mathrm{PLCO}_{\mathrm{m} 2012}$ criteria; $15.2 \%$ would be eligible according to both criteria sets (Box 3). This suggests that about 450000 individuals in Australia may be eligible for lung cancer screening. 
1 Demographic characteristics of ever-smokers in the Busselton Healthy Ageing Study

\begin{tabular}{|c|c|c|}
\hline & \multicolumn{2}{|c|}{$50-68$ years old $55-68$ years old } \\
\hline Number & 1867 & 1260 \\
\hline Age (years), mean $\pm S D$ & $58.0 \pm 4.8$ & $60.7 \pm 3.4$ \\
\hline Sex (women) & $927(49.7 \%)$ & $603(47.9 \%)$ \\
\hline \multicolumn{3}{|l|}{ Ethnic background } \\
\hline European & $1848(99.0 \%)$ & $1249(99.1 \%)$ \\
\hline Asian & $12(0.6 \%)$ & $5(0.4 \%)$ \\
\hline Aboriginal and/or Torres Strait Islander & $6(0.3 \%)$ & $5(0.4 \%)$ \\
\hline Māori or Pacific Islander & $1(0.1 \%)$ & $1(0.1 \%)$ \\
\hline Body mass index $\left(\mathrm{kg} / \mathrm{m}^{2}\right)$, mean $\pm \mathrm{SD}$ & $28.46 \pm 4.90$ & $28.70 \pm 4.95$ \\
\hline \multicolumn{3}{|l|}{ Smoking status } \\
\hline Current & $368(19.7 \%)$ & $240(19.0 \%)$ \\
\hline Former & $1499(80.3 \%)$ & $1020(81.0 \%)$ \\
\hline \multicolumn{3}{|l|}{ Total pack-years, mean \pm SD } \\
\hline Ever-smokers & $19.2 \pm 19.6$ & $20.5 \pm 20.7$ \\
\hline Current smokers & $31.5 \pm 20.0$ & $32.1 \pm 19.3$ \\
\hline Former smokers & $16.2 \pm 18.4$ & $17.8 \pm 20.1$ \\
\hline \multicolumn{3}{|l|}{ Highest education level obtained } \\
\hline Did not complete high school & $36(1.9 \%)$ & $27(2.1 \%)$ \\
\hline High school & $1000(53.6 \%)$ & $702(55.7 \%)$ \\
\hline TAFE or other college & $555(29.7 \%)$ & $352(27.9 \%)$ \\
\hline University & $276(14.8 \%)$ & $179(14.2 \%)$ \\
\hline $\begin{array}{l}\text { Previous cancer (excluding non- } \\
\text { melanomatotic skin cancer) }\end{array}$ & $155(8.3 \%)$ & $122(9.7 \%)$ \\
\hline Family history of lung cancer & $146(7.8 \%)$ & $106(8.4 \%)$ \\
\hline \multicolumn{3}{|c|}{ Chronic obstructive pulmonary disease (COPD) } \\
\hline Self-reported COPD & $16(0.9 \%)$ & $13(1.0 \%)$ \\
\hline Symptoms consistent with COPD & $617(33.0 \%)$ & $441(35.0 \%)$ \\
\hline Spirometry-defined COPD & $179 / 1191(15.0 \%)$ & 108/782 (13.8\%) \\
\hline
\end{tabular}

TAFE $=$ Technical and Further Education.

\section{Effect of COPD definition on lung cancer risk and eligibility}

Of the ever-smokers in the BHAS population, 1191 had concurrent spirometry, of whom 782 were aged 55-68 years. Using the $\mathrm{PLCO}_{\mathrm{m} 2012}$ criteria, the proportion eligible for screening was $16.4 \%$ (using selfreported COPD), $18.8 \%$ (symptoms consistent with COPD), or $17.5 \%$ (airflow obstruction on spirometry) (Box 4). Fewer people were eligible for screening using selfreported than spirometry-defined COPD $(P<0.01)$; there was no statistical difference between the proportions of eligible participants when spirometry-defined or symptomdefined COPD was used $(P=0.06)$.
When spirometry-defined COPD was added to symptom-defined COPD to determine $\mathrm{PLCO}_{\mathrm{m} 2012}$ risk, an additional seven participants $(0.9 \%)$ would have been eligible for screening. If normal spirometry was used to exclude COPD in those who reported symptoms of COPD, 17 participants $(2.1 \%)$ would be deemed ineligible for screening.

Of the 409 ever-smokers aged 50-55 years (and therefore ineligible for screening according to current criteria) with spirometry data, 18 (4.4\%; 95\% CI, 2.8-6.9\%), 36 (8.8\%; $95 \% \mathrm{CI}, 6.4-11.9 \%)$ or $25(6.1 \%$; $95 \%$ CI, 4.2-8.9\%) would have been eligible based on a $\mathrm{PLCO}_{\mathrm{m} 2012}$ risk greater than $1.5 \%$ when COPD was defined by doctor diagnosis, symptoms, or spirometry respectively.

\section{Discussion}

Our study suggests that $17.9 \%$ $\left(\mathrm{PLCO}_{\mathrm{m} 2012}\right)$ to $20.1 \%$ (USPSTF criteria) of current or former smokers aged 55-68 years in Busselton would be eligible for lung cancer screening, corresponding to $8.9 \%\left(\mathrm{PLCO}_{\mathrm{m} 2012}\right)$ and $10 \%$ (USPSTF) of all those in the BHAS cohort aged 55-68 years. This is the first time that the proportion of ever-smokers eligible for lung cancer screening has been estimated in an Australian population. While small studies have shown the feasibility of lung cancer screening in Australia, significant hurdles remain before screening is endorsed locally. ${ }^{15-18}$

Our finding that the USPSTF criteria identified a higher proportion of eligible individuals than the $\mathrm{PLCO}_{\mathrm{m} 2012}$ criteria is consistent with previous reports. ${ }^{9}$ Our study could not validate the predictive performance of each criterion because mature lung cancer outcomes were not available. Retrospective studies suggest that the $\mathrm{PLCO}_{\mathrm{m} 2012}$ model performs better than the USPSTF criteria in identifying high risk individuals, but prospective impact analyses in screening cohorts are required to determine which eligibility criteria should be preferred in the Australian context.

There have been four previous estimates of the proportion of the US population who would be eligible for screening (Box 5). ${ }^{9,19-21}$ Three of these studies estimated that $18.8-24.4 \%$ of ever-smokers and $10.5-14.3 \%$ of all individuals in the respective age cohorts were eligible for screening according to USPSTF criteria. ${ }^{19-21}$ These estimates are broadly comparable with our estimates of the proportion of eligible individuals in the BHAS. On the other hand, fewer BHAS ever-smokers would be eligible for screening than estimated for the PLCO intervention arm eversmokers $(17.9 \%$ v 34.6\%; $P<0.001) .{ }^{9}$ This observation may partly be explained by differences in tobacco exposure between the cohorts; the 


\section{Eligibility for lung cancer screening of 1260 55-68-year-old ever-smokers in Busselton, according to USPSTF and $\mathrm{PLCO}_{\mathrm{m} 2012}$} criteria*

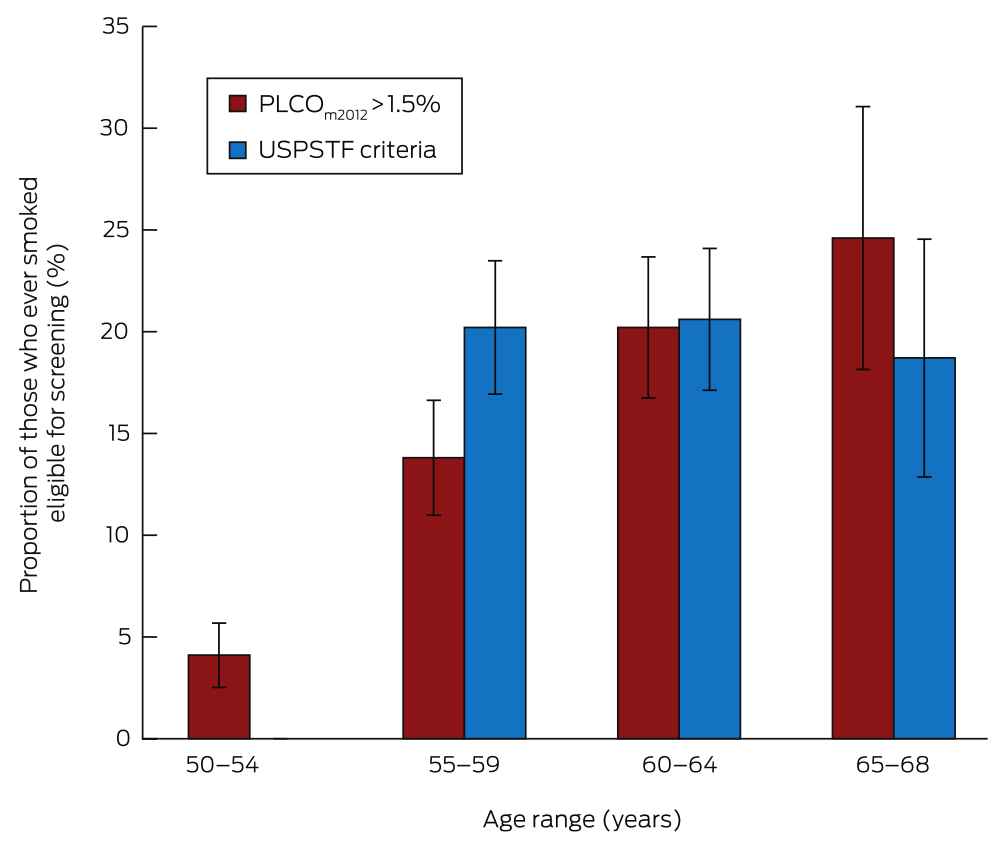

$\mathrm{PLCO}=$ Prostate, Lung, Colorectal, Ovarian Screening Trial; USPSTF $=$ US Preventive Service Task Force. *Calculated using doctor-diagnosed chronic obstructive pulmonary disease, with $95 \%$ confidence intervals.

3 Schematic representation of the proportion of current and former smokers eligible for screening

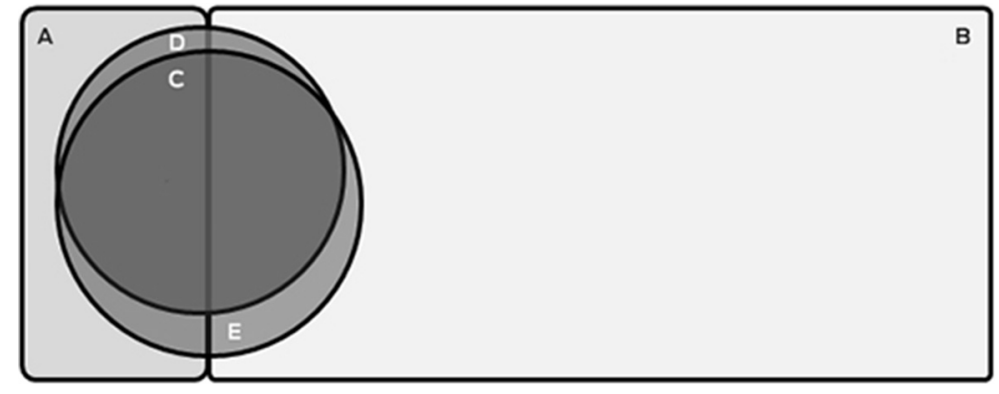

$\mathrm{A}=$ Ineligible current smokers $(n=103 ; 8.2 \%) ; \mathrm{B}=$ Ineligible former smokers $(n=870 ; 69.0 \%)$; $\mathrm{C}=$ Individuals eligible on both USPSTF and PLCO 2012 criteria $(n=192 ; 15.2 \%) ; \mathrm{D}=$ Individuals eligible only on $\mathrm{PLCO}_{\mathrm{m} 2012}$ criteria $(n=33 ; 2.6 \%) ; \mathrm{E}=$ Individuals eligible only on USPSTF criteria $(n=62 ; 4.9 \%)$. The areas of the components of this figure are approximately proportional.

\section{Proportions of 782 ever-smokers aged 55-68 years eligible for screening based on $\mathrm{PLCO}_{\mathrm{m} 2012}$ criteria, using different definitions of chronic obstructive pulmonary disease (COPD)}

\section{COPD definition for estimating}

$\mathrm{PLCO}_{\mathrm{m} 2012}$ lung cancer risk

Self-reported COPD

Symptom-defined COPD

\begin{tabular}{cc}
$\mathrm{PLCO}_{\mathrm{m} 2 \mathrm{O} 12}$ risk $>1.5 \%$ & $P^{*}$ \\
\hline $128(16.4 \% ; 95 \% \mathrm{Cl}, 13.8-19.0 \%)$ & $<0.01$ \\
$147(18.8 \% ; 95 \% \mathrm{Cl}, 16.1-24.5 \%)$ & 0.06 \\
$137(17.5 \% ; 95 \% \mathrm{Cl}, 14.8-20.2 \%)$ & -
\end{tabular}

Spirometry-defined COPD

137 (17.5\%; 95\% Cl, 14.8-20.2\%)

* $v$ spirometry-defined COPD (McNemar test). proportion of current and former smokers were similar, but BHAS participants reported lower smoking intensity (mean pack-years, BHAS $v$ PLCO: current smokers, $32.1 v 40.8$, $P<0.001$; former smokers, $17.8 v 25.8$; $P<0.001){ }^{22}$

There are two possible explanations for the lower smoking intensity in the BHAS cohort. The first relates to historical trends in smoking. Enrolment for the PLCO trial occurred between 1993 and 2001, whereas BHAS enrolment commenced in 2010. ${ }^{14,23}$ Smoking consumption in Australia declined significantly between 2001 and 2010 among both men and women. ${ }^{24}$ The second explanation is a potential healthy community effect after repeated cross-sectional health surveys in the Busselton community since $1966 .^{14}$

The current study has highlighted the known challenges in defining and diagnosing COPD. Only 1\% of 55-68year-old BHAS ever-smokers reported being diagnosed with COPD, whereas $13.8 \%$ met the spirometric definition of COPD and $35.0 \%$ reported symptoms consistent with the disease. A similar discrepancy was previously described in a larger Australian study. ${ }^{10}$ Airflow obstruction on spirometry is not only crucial to diagnosing COPD, but is an independent predictor of increased lung cancer incidence in screening studies, and may predict overdiagnosis. ${ }^{12}$ Incorporating spirometry into screening eligibility assessment has been suggested, but this would require direct patient contact. $^{12}$ Our results suggest that performing spirometry is unlikely to meaningfully improve the identification of eligible individuals, with just one additional individual from every 100 ever-smokers assessed becoming eligible. We therefore contend that, in the absence of more epidemiological data comparing the relative lung cancer risks associated with airflow obstruction and with symptoms or self-reported COPD, defining COPD on the basis of symptoms is an appropriate surrogate measure for spirometry.

Policy makers in jurisdictions that recommend population-based cancer screening, such as Australia, are faced by significant implementation 
5 Summary of studies reporting proportions of the population aged 55 years or more who are eligible for lung cancer screening

\begin{tabular}{|c|c|c|c|c|c|}
\hline & BHAS & $\begin{array}{c}\text { PLCO } \\
\text { intervention } \text { arm }^{9,22}\end{array}$ & $\begin{array}{l}\text { US Health and } \\
\text { Retirement Study }\end{array}$ & $\begin{array}{l}\text { US National Health } \\
\text { Interview Survey }{ }^{20}\end{array}$ & $\begin{array}{l}\text { US National Health } \\
\text { and Nutrition } \\
\text { Examination Survey }{ }^{18}\end{array}$ \\
\hline Sample size & 2523 & 77445 & 16901 & 7138 & 2562 \\
\hline Recruitment period & $2010-2013$ & $1993-2001$ & 2012 & 2011 & 2007-2012 \\
\hline Age range, years & $55-68$ & $55-74$ & $55-80$ & $55-74$ & $55-77$ \\
\hline \multicolumn{6}{|l|}{ Smoking status } \\
\hline Never & $49.2 \%$ & $45.1 \%$ & $42.5 \%$ & $N R$ & NR \\
\hline Current & $9.5 \%$ & $10.4 \%$ & $14.4 \%$ & NR & NR \\
\hline Former & $40.4 \%$ & $42.0 \%$ & $39.6 \%$ & NR & NR \\
\hline Missing or incomplete & $0.9 \%$ & $2.5 \%$ & $3.5 \%$ & NR & NR \\
\hline \multicolumn{6}{|c|}{ Eligible individuals as proportion of entire cohort } \\
\hline USPSTF criteria & $10.0 \%$ & $19.6 \%$ & $10.5 \%$ & $14.3 \%$ & NR \\
\hline $\mathrm{PLCO}_{\mathrm{m} 2012}>1.5 \%$ & $8.9 \%$ & $17.9 \%$ & NR & NR & NR \\
\hline \multicolumn{6}{|c|}{ Eligible individuals as proportion of cohort of all ever-smokers } \\
\hline USPSTF criteria & $20.1 \%$ & $38.0 \%$ & $18.8 \%$ & NR & $24.4 \%$ \\
\hline $\mathrm{PLCO}_{\mathrm{m} 2012}>1.5 \%$ & $17.9 \%$ & $34.6 \%$ & NR & NR & $\begin{array}{c}\text { 9-35\%, depending } \\
\text { on ethnicity* }\end{array}$ \\
\hline
\end{tabular}

$\mathrm{BHAS}=$ Busselton Healthy Ageing Study; NR = not reported; PLCO=Prostate, Lung, Colorectal and Ovarian Trial; USPSTF=United States Preventive Services Task Force. * Extrapolated from figure 1 in reference 18.

challenges. $^{15,25}$ No state or federal database contains the necessary data for directly identifying the estimated $10 \%$ of the age-defined population eligible for screening. Populationbased recruitment strategies for lung cancer screening must therefore currently engage with and assess the eligibility of a broader population of ever-smokers, the majority of whom will be ineligible. The feasibility and unintentional impact of this recruitment approach is not known.

Smoking cessation in one lung cancer screening study reduced all-cause mortality by up to $43 \%{ }^{26}$ Almost half of BHAS current smokers $(42.9 \% ; 103$ of 240 current smokers) were ineligible for screening, regardless of the criteria used. Providing smoking cessation support without LDCT screening to ineligible current smokers who engage with a screening program may be a pragmatic way to combine primary prevention and early detection of lung cancer.

Of the BHAS ever-smokers aged 50-55 years, $4.4-8.8 \%$ had PLCO $_{\mathrm{m} 2012}$ lung cancer risk sufficient to potentially benefit from screening, depending on the definition of COPD used. This may represent an additional population at risk who may benefit from lung cancer screening at a lower age threshold than currently recommended, although internationally there is little prospect of such a change. ${ }^{27}$

There are several potential limitations to this study. The upper age limit of our BHAS participants was 68 years, younger than the maximum recommended screening age of 80 years. ${ }^{3}$ This study may therefore have underestimated the proportion of the population potentially eligible for screening, as $\mathrm{PLCO}_{\mathrm{m} 2012}$ risk increases with age. ${ }^{21}$ Ethnic background has an impact on lung cancer risk, and the BHAS participants were almost exclusively European in origin, which is not representative of the broader Australian population, although the Busselton population age distribution and smoking demographic can be broadly generalised to the wider Australian population. Other lung cancer risk prediction models are being used to select individuals for lung cancer screening studies, but it was not possible to assess them, as they include variables (such as asbestos exposure) not recorded by the BHAS. ${ }^{6}$ The definition of COPD in the $\mathrm{PLCO}_{\mathrm{m} 2012}$ model is selfreported COPD, chronic bronchitis or emphysema, more inclusive than the definition used in the BHAS. We were unable to validate the $\mathrm{PLCO}_{\mathrm{m} 2012}$ model, as 6-year lung cancer outcomes are not available.

In conclusion, we estimate that between $17.9 \%$ and $20.1 \%$ of all current or former smokers aged 55-68 years in the BHAS population would be eligible for lung cancer screening, depending on the criteria applied. Symptomdefined COPD may be an appropriate surrogate measure for spirometric testing for determining the presence of COPD as part of the assessment of lung cancer screening eligibility.

Acknowledgements: Funding was provided by the Western Australian Cancer and Palliative Care Network for a Clinical Cancer Fellowship for David Manners. We acknowledge the Western Australian Country Health Service - South West for core infrastructure support, Marianne Weber for assistance with the PLCO $\mathrm{m}_{2012}$ model, and the residents of Busselton Shire for participating in the study. The baseline survey of the Busselton Healthy Ageing Study was funded by grants from the Office of Science and the Department of Health of the Government of Western Australia (grant numbers G05911, G0630I), the City of Busselton, a bequest of the late Janet Elder, and private donors.

Competing interests: No relevant disclosures.

Received 12 Jan 2016, accepted 12 Apr 2016. .

(c) 2016 AMPCo Pty Ltd. Produced with Elsevier B.V. All rights reserved. 
1 Australian Institute of Health and Welfare, Cancer Australia. Lung cancer in Australia: an overview (Cat. No. CAN 58; Cancer Series No. 64). Canberra: AlHW, 2011. http://www.aihw.gov.au/ WorkArea/DownloadAsset.aspx?id=1 $0737421095 \&$ liblD=10737421094 (accessed Feb 2016).

2 Aberle DR, Adams AM, Berg CD, et al. Reduced lung-cancer mortality with low-dose computed tomographic screening. N Engl J Med 2011; 365: 395-409.

3 Moyer VA. Screening for lung cancer: US Preventive Services Task Force recommendation statement. Ann Intern Med 2014; 160: 330-338.

4 Kovalchik SA, Tammemägi M, Berg CD, et al. Targeting of low-dose CT screening according to the risk of lungcancer death. N Engl J Med 2013; 369: 245-254.

5 Black WC, Gareen IF, Soneji SS, et al. Cost-effectiveness of CT screening in the national lung screening trial. $N$ Engl J Med 2014; 371: 1793-1802.

6 Field JK, Duffy SW, Baldwin DR, et al. UK Lung Cancer RCT Pilot Screening Trial: baseline findings from the screening arm provide evidence for the potential implementation of lung cancer screening. Thorax 2015; 71: 161-170.

7 Kauczor HU, Bonomo L, Gaga M, et al. ESR/ERS white paper on lung cancer screening. Eur Radiol 2015; 25: 2519-2531.

8 Tammemägi MC, Katki HA, Hocking WG, et al. Selection criteria for lungcancer screening. N Engl J Med 2013; 368: 728-736.

9 Tammemägi MC, Church TR, Hocking WG, et al. Evaluation of the lung cancer risks at which to screen ever- and never-smokers: screening rules applied to the PLCO and NLST cohorts. PLoS Med 2014; 11: el001764.

10 Toelle BG, Xuan W, Bird TE, et al. Respiratory symptoms and illness in older Australians: the Burden of Obstructive Lung Disease (BOLD) study. Med J Aust 2013; 198: 144-148. https://www.mja.com.au/journal/2 013/198/3/respiratory-symptoms-and- illness-older-australians-burdenobstructive-lung

1 Tammemägi MC, Lam SC, McWilliams AM, et al. Incremental value of pulmonary function and sputum DNA image cytometry in lung cancer risk prediction. Cancer Prev Res (Phila) 2011; 4: 552-561.

12 Young RP, Duan F, Chiles C, et al. Airflow limitation and histology shift in the National Lung Screening Trial. The NLST-ACRIN Cohort Substudy. Am J Respir Crit Care Med 2015; 192: 1060-1067.

13 Australian Bureau of Statistics. 4364.0 55.001. Australian Health Survey: first results, 2011-12. Canberra: ABS, 2012. http://www.abs.gov.au/AUSSTATS/ abs@.nsf/Lookup/4364.0.55.001 Main+Features12011-12? OpenDocument (accessed Feb 2016).

14 James A, Hunter M, Straker L, et al. Rationale, design and methods for a community-based study of clustering and cumulative effects of chronic disease processes and their effects on ageing: the Busselton healthy ageing study. BMC Public Health 2013; 13: 936.

15 Brims F, McWilliams A, Fong K. Lung cancer screening in Australia: progress or procrastination? Med J Aust 2016; 204: 4-5. https://www.mja.com.au/ journal/2016/204///lung-cancerscreening-australia-progress-orprocrastination

16 Brims FJ, Murray CP, de Klerk N, et al. Ultra-low-dose chest computer tomography screening of an asbestosexposed population in Western Australia. Am J Respir Crit Care Med 2015; 191: 113-116.

17 Marshall HM, Bowman RV, Ayres J, et al. Lung cancer screening feasibility in Australia. Eur Respir J 2015; 45: 1734-1737.

18 Department of Health, Standing Committee on Screening. Position statement. Lung cancer screening using low-dose computed tomography. 2015. http://www.cancerscreening.gov.au/ internet/screening/publishing.nsf/ Content/lung-cancer-screening (accessed Feb 2016).
19 Fiscella K, Winters P, Farah S, et al. Do lung cancer eligibility criteria align with risk among Blacks and Hispanics? PLoS One 2015; 10: e0143789.

20 Howard DH, Richards TB, Bach PB, et al. Comorbidities, smoking status, and life expectancy among individuals eligible for lung cancer screening. Cancer 2015; 121: 4341-4347.

21 Ma J, Ward EM, Smith R, et al. Annual number of lung cancer deaths potentially avertable by screening in the United States. Cancer 2013; 119: 1381-1385.

22 Tammemägi MC, Pinsky PF, Caporaso NE, et al. Lung cancer risk prediction: prostate, lung, colorectal and ovarian cancer screening trial models and validation. J Natl Cancer Inst 2011; 103: 1058-1068.

23 Oken MM, Hocking WG, Kvale PA, et al. Screening by chest radiograph and lung cancer mortality: the Prostate, Lung, Colorectal, and Ovarian (PLCO) Randomized Trial. JAMA 2011; 306: 1865-1873.

24 Scollo M, Winstanley MH. Tobacco in Australia: facts and issues. Fourth edition. Melbourne: Cancer Council Victoria, 2012. http://www. tobaccoinaustralia.org.au (accessed Feb 2016).

25 Australian Population Health Development Principal Committee, Screening Subcommittee. Population based screening framework. Canberra: Australian Health Ministers' Council, 2008. http://www.cancerscreening.gov. au/internet/screening/publishing.nsf/ Content/16AE0B0524753EE9CA257 CEE0000B5D7/\$File/Populationbased-screening-framework.PDF (accessed Feb 2016).

26 Pastorino U, Boffi R, Machianò A, et al. Stopping smoking reduces mortality in low-dose computed tomography (LDCT) screening volunteers. J Thorac Oncol 2016; doi: http://dx.doi.org/ 10.1016/j.jtho.2016.02.011 [Epub ahead of print].

27 Field JK, Devaraj A, Duffy SW, et al. CT screening for lung cancer: Is the evidence strong enough? Lung Cancer 2016; 91: 29-35. 